\section{Sistem Kelistrikan Rsud Ulin Yang Handal Menggunakan Distribusi Jaringan Listrik Tegangan Menengah $20 \mathrm{Kv}$ Terintegrasi}

\section{Akhmad Ramadhani}

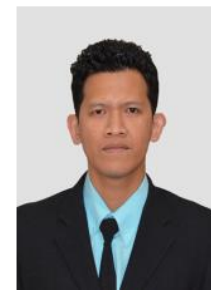

Akhmad Ramadhani lahir pada Tanggal 1 Juni 1984. Lulus dari Pendidikan Magister Teknik Elektro Konsentrasi Sistem Tenaga Listrik pada Institut Teknologi Sepuluh Nopember Surabaya. Memiliki beberapa paper baik nasional maupun internasional, Disiplin ilmu yang disukai yaitu Artificial Intellegence, Renewble Energy, Managemen Energy, Automation Control System,dll buletinppi@ulm.ac.id
Rumah sakit adalah tempat pelayanan publik yang sangat penting, dimana pelayanan tersebut tidak terlepas dengan kebutuhan listrik. Adapun kendala dari sistem kelistrikan RSUD ULIN yaitu masih menggunakan jaringan distribusi tegangan rendah, padahal jarak antara gardu PLN dengan gedung cukup jauh sehingga tegangannya droop. Akibatnya sangat mempengarui supply listrik kegedung tersebut, sehingga peralatan medik maupun non medik cepat mengalami kerusakan. Selain itu sistem beckup powernya masih partial artinya setiap gedung memiliki genset masing-masing sehingga jika genset tersebut bermasalah maka genset lain tidak bisa membantu supply listrik kegedung tersebut. Untuk mengatasi permasalahan tersebut, RSUD ULIN menggunakan distribusi jaringan listrik tegangan menengah sehingga permasalahan droop tegangan dapat teratasi kemudian sistem beckup listriknya sudah menggunakan sistem Automatic Transfer Switch (ATS) tegangan menengah yang dilengkapi dengan panel sinkrone full otomatis. Sistem backup listriknya sudah menggunakan managemen energi sehingga genset yang hidup menyesuaikan dengan beban yang ada di RSUD Ulin sehingga menghemat penggunaan bahan bakar dan mendukung efisiensi energi.

Kata kunci : tegangan droop, distribusi jaringan listrik tegangan menengah, RSUD ULIN

www.buletinppi.ulm.ac.id

\section{Pendahuluan}

Rumah Sakit Umum Daerah Ulin Banjarmasin adalah tempat pelayanan publik yang sangat penting yang tidak terlepas dengan kebutuhan Listrik. Karena hampir sebagian besar pelayanan dan penunjang medik sangat memerlukan supply energy listrik. Karena pada gedung IGD Terpadu terdapat kamar operasi,ICU/ICCU, Hemodialisa, Bayi, VK bersalin, Cath Lab, ESWL, Endoscopy , IGD sendiri dimana pada ruangan tersebut terdapat peralatan medik yang berbasis komputer, sehingga jika terjadi pemadaman listrik maka akan merestart sistem komputer alat medik tersebut. Hal tersebut sangat tidak direkomendasikan karena posisi pasien masih dalam proses perawatan atau tindakan sehingga dapat menggangu proses tindakan tersebut.

Adapun kendala lain dari sistem kelistrikan RSUD ULIN yaitu masih menggunakan jaringan distribusi tegangan rendah padahal jarak antara gardu PLN dengan gedung cukup jauh sehingga tengan yang disupply droop sehingga sangat mempengarui supply listrik kegedung tersebut. akibatnya peralatan baik medik maupun non medik cepat mengalami kerusakan. Selain itu sistem beckup listriknya masih partial artinya setiap gedung memiliki genset masing-masing sehingga jika genset tersebut bermasalah maka genset lain tidak bisa membantu untuk supply listrik kegedung tersebut.

Untuk mengatasi permasalahan tersebut RSUD ULIN menggunakan distribusi jaringan listrik tegangan menengah sehingga permasalahan droop tegangan dapat teratasi kemudian sistem beckup listriknya sudah menggunakan sistem automatic transfer switch (ATS) tegangan menengah yang dilengkapi dengan panel

sinkron full otomatis. Sistem kontrol gensetnya sudah menggunakan managemen energi sehingga genset yang hidup menyesuaikan dengan beban yang ada di RSUD Ulin sehingga sudah menghemat penggunaan bahan bakar jadi mendukung efisiesnsi energi yang sudah diperintahkan oleh pemerintah daerah dan pemerintah pusat

\section{Hasil Kerja}

\section{Analisis Masalah Kelistrikan RSUD ULIN Eksisting}

RSUD ULIN merupakan rumah sakit type A Pendidikan yang merupakan pusat rujukan rumah sakit Kalimantan Selatan dan Tengah. Tetapi memiliki permasalahan dalam sistem kelistrikannya, yaitu jarak antara gardu PLN dengan gedung cukup jauh sedangkan tegangan yang digunakan adalah tegangan rendah (TR) sehingga terjadi droop tegangan yang cukup besar (Imam Robandi, 2006). Hal ini menyebabkan beberapa peralatan seperti Lift, Air Conditioning (AC), Komputer, dan Peralatan Medik tidak bisa berfungsi optimal sehingga peralatan tersebut jadi cepat rusak. Karena sesuai rumus tegangan drop (John J.Grainger, William D Stevension JR , 1994) adalah sebagai berikut:

$\Delta U=U_{1}-U_{2} \cong \frac{R P+X Q}{U_{2}}$ 
Dimana $: R=$ Tahanan Kabel

$X=$ Reaktansi Kabel

$P=$ Daya Aktif

$Q=$ Daya Reaktif

Berikut blok diagram sistem kelistrikan RSUD ULIN eksisting menggunakan distribusi jaringan listrik tegangan rendah (lihat Gambar 1).

Gambar 3. Simulasi Aliran Daya Menggunakan Software

ETAP 11

Dari simulasi aliran daya menggunakan software ETAP terhadap sistem kelistrikan RSUD ULIN tegangan rendah (lihat Gambar 3) terdapat penurunan tegangan

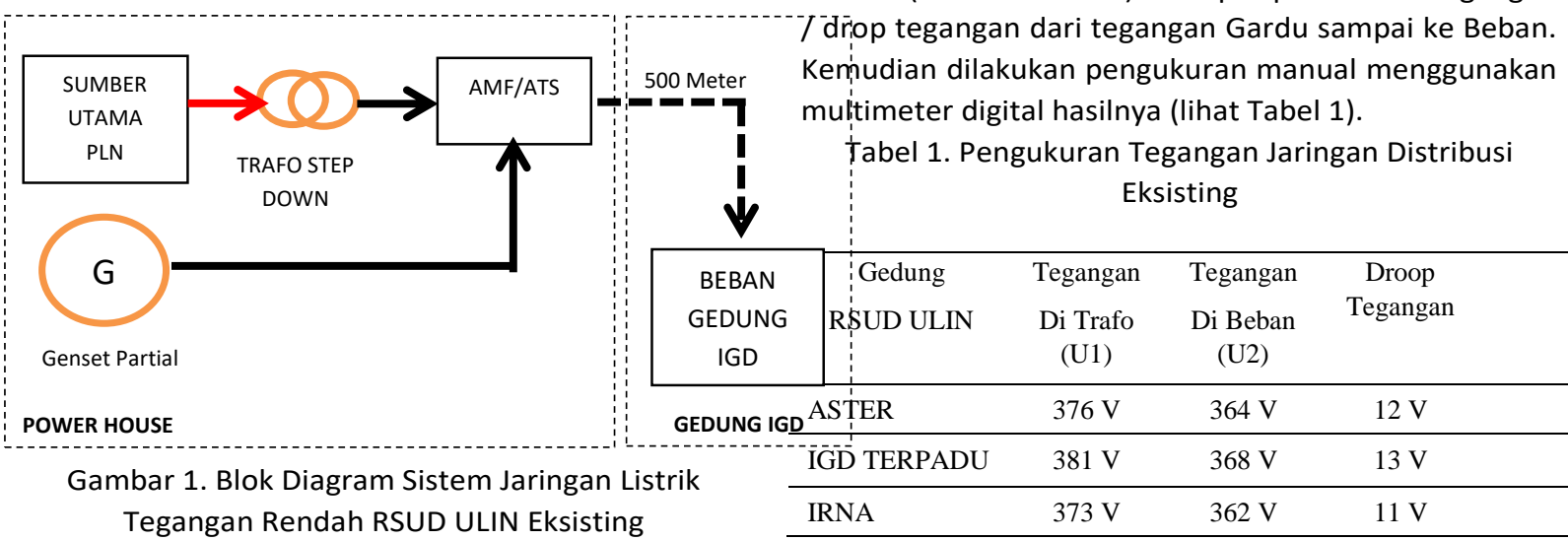

Kemudian kelistrikan RSUD ULIN Eksisting digambar menggunakan software ETAP 11 agar mempermudah melakuan simulasi dan analisa sistemnya sebagai berikut :

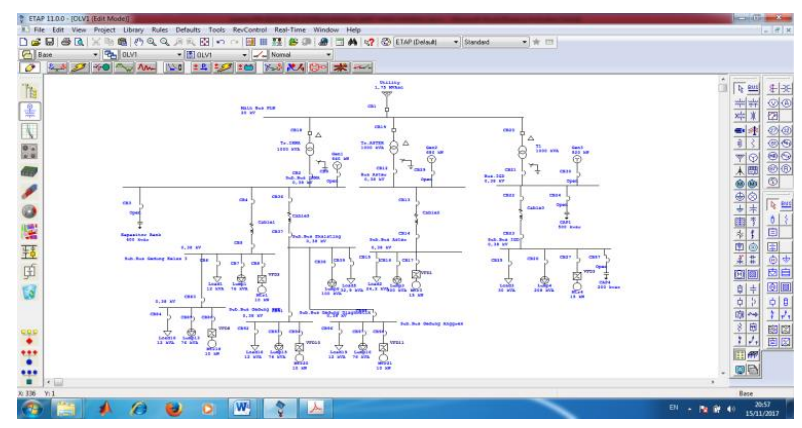

Gambar 2. Single Line Kelistrikan RSUD ULIN Tegangan Rendah menggunakan software ETAP 11

Adapun hasil simulasi Load Flow (Hadi Saadat, 1999) sistem kelistrikan tersebut (lihat Gambar 2) nantinya akan di bandingkan dengan pengukuran di lapangan menggunakan alat ukur digital sebagai berikut :

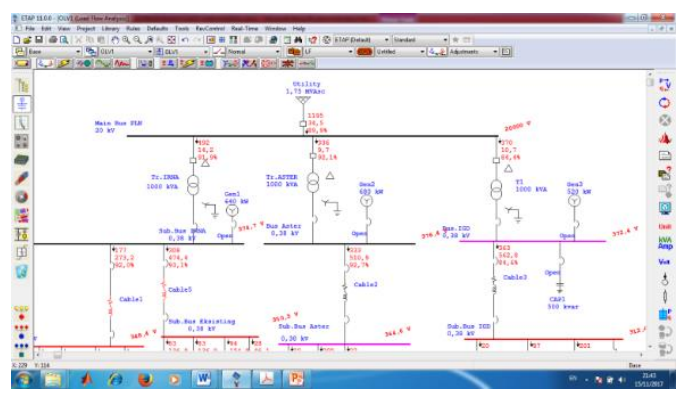

Dari hasil simulasi menggunakan software dan pengukuran dilapangan maka ada beberapa permasalahan sistem kelistrikan jaringan tegangan rendah RSUD ULIN adalah sebagai berikut :

1) Sehubungan jarak antara power house (Gardu) ke gedung cukup jauh sehingga terjadi Looses atau droop tegangan sehingga menyebabkan beberapa peralatan elektronik tidak bisa berfungsi optimal (lihat Tabel 1).

2) Sistem Distribusi Jaringan Listriknya masih Partial tidak integrated sehingga jika salah satu sistem bermasalah maka jaringan listrik lain tidak bisa membantu padahal dalam rumah sakit tidak boleh ada padam listrik.

3) Sistem Gensetnya masih partial tidak singkronizing sehingga terjadi pemborosan bahan bakar karena walaupun beban kecil maka genset harus tetap di hidupkan.

4) Dari permasalahan kelistrikan tersebut maka muncul pemikiran untuk menerapkan sistem distribusi tegangan menengah $20 \mathrm{KV}$ yang terintegrasi yang akan dijelaskan pada bab berikutnya.

\section{Aplikasi Kelistrikan RSUD ULIN Menggunakan Sistem Distribusi Tegangan Menengah 20 KV Terintegrasi}

Sehubungan dengan permasalahan kelistrikan RSUD ULIN yang masih belum handal salah satunya terjadinya looses, penyebabnya karena jarak dari gardu PLN ke gedung pelayanan cukup jauh Selain itu sistem beckup powernya masih partial artinya setiap gedung memiliki genset masing-masing sehingga jika genset tersebut bermasalah maka genset lain tidak bisa membantu 
untuk supply listrik kegedung tersebut (Imam Robandi, 2009). Oleh sebab itu untuk mengurangi looses tersebut maka sistem distribusi listrik kawasan RSUD ULIN menggunakan tegangan menengah $20 \mathrm{KV}$ yang terintegrasi. Sistem distribusi jaringan tegangan menegah tersebut terdiri dari dua sumber yaitu:

1. Sumber Utama dari PLN $20 \mathrm{KV}$

2. Sumber Cadangan dari Genset yang memiliki fasilitas Automatic Sincrone yang di step up ke $20 \mathrm{KV}$

Untuk lebih jelasnya berikut blok diagram sistem kelistrikan RSUD ULIN menggunakan Distribusi Jaringan Listrik Tegangan Menengah 20 KV (lihat Gambar 4).
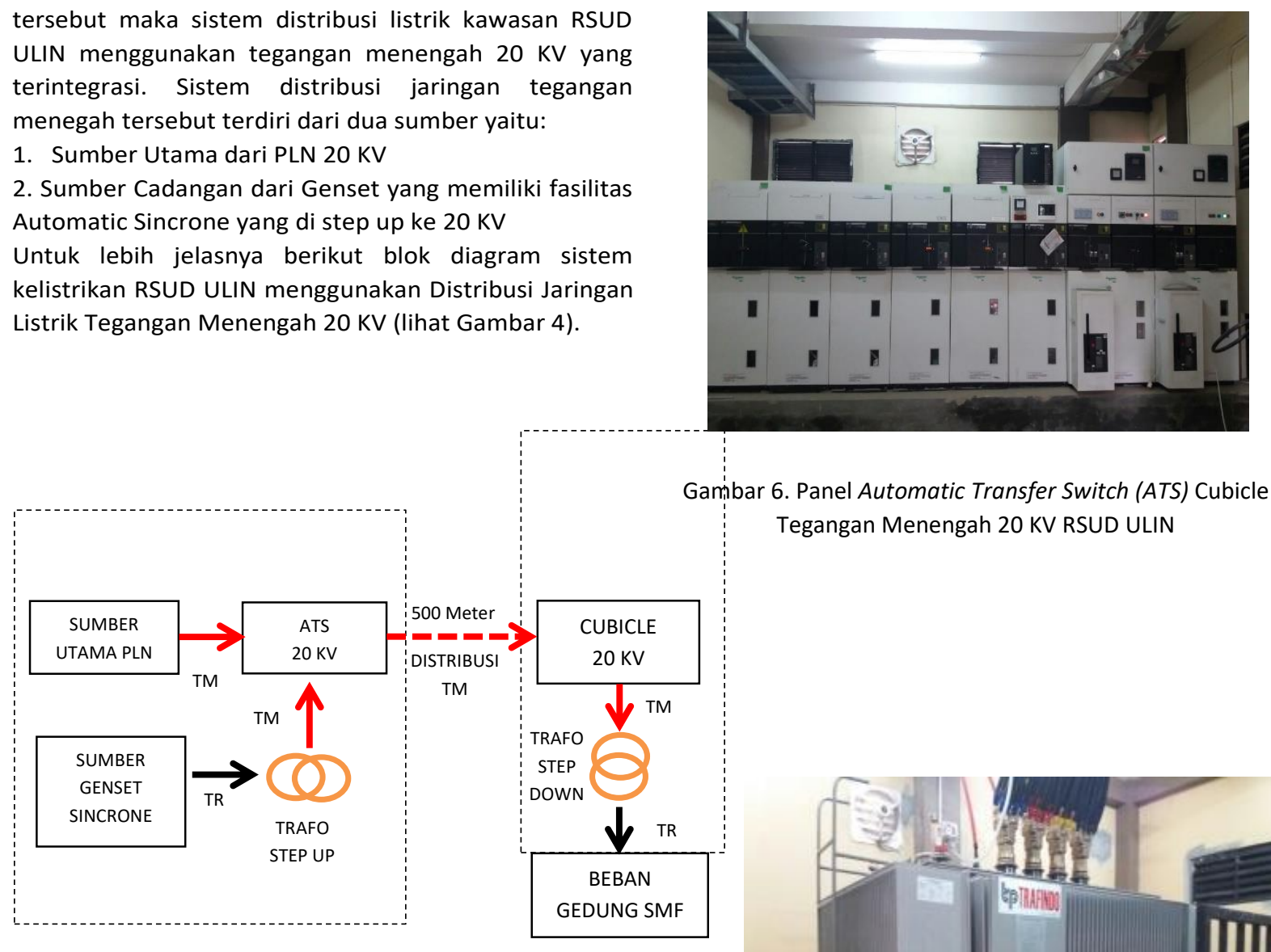

GARDU LISTRIK

GEDUNG SMF

Gambar 4. Blok Diagram Sistem Distribusi Jaringan Listrik Tegangan Menengah RSUD ULIN

Adapun Single Line Diagram Distribusi Listrik Tegangan Menengah 20 KV RSUD ULIN terintegrasi yang sudah diaplikasikan (lihat Gambar 5).

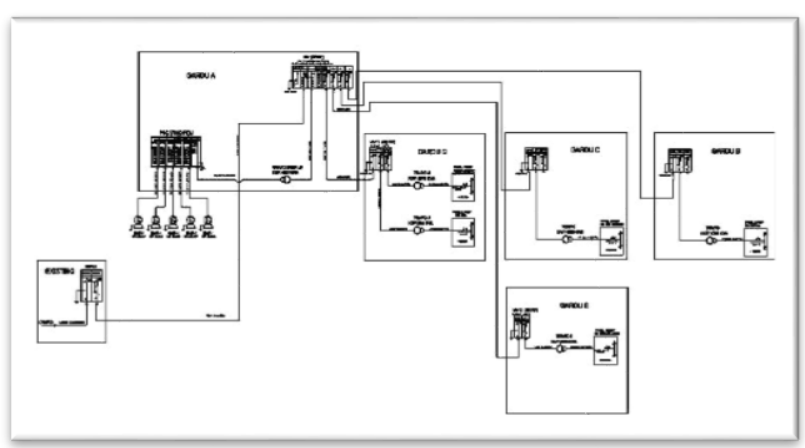

Gambar 5. Single Line Diagram Distribusi Listrik Tegangan Menengah $20 \mathrm{KV}$ terintegrasi RSUD ULIN

Berikut gambar panel cubicle (lihat Gambar 6), trafo step up (lihat Gambar 7), panel sincrone (lihat Gambar 8) dan genset RSUD ULIN (lihat Gambar 9) yang telah mengggunakan sistem kelistrikan menggunakan jaringan distribusi tegangan menengah $20 \mathrm{KV}$ terintegrasi tersebut sesuai single line diagram (lihat Gambar 5).

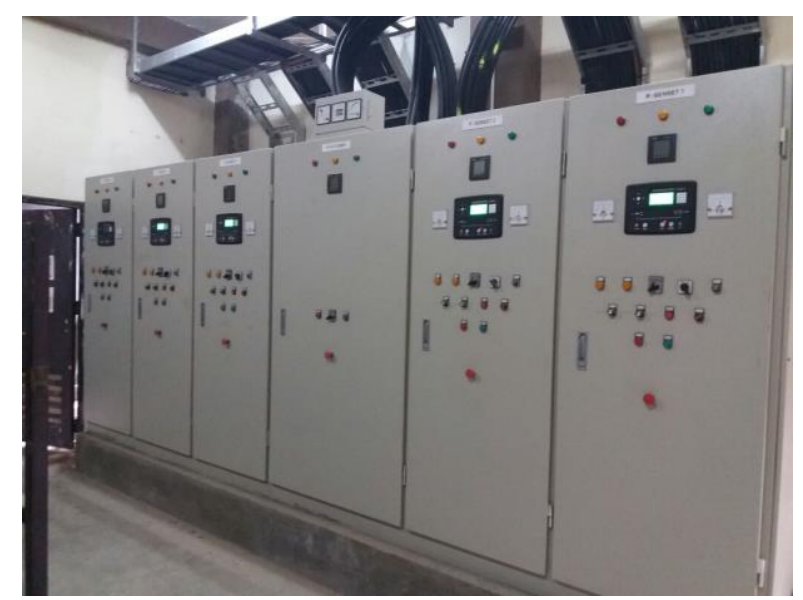

Gambar 8. Panel Sincrone 5x 800 KVA dengan feature managemen energy system 


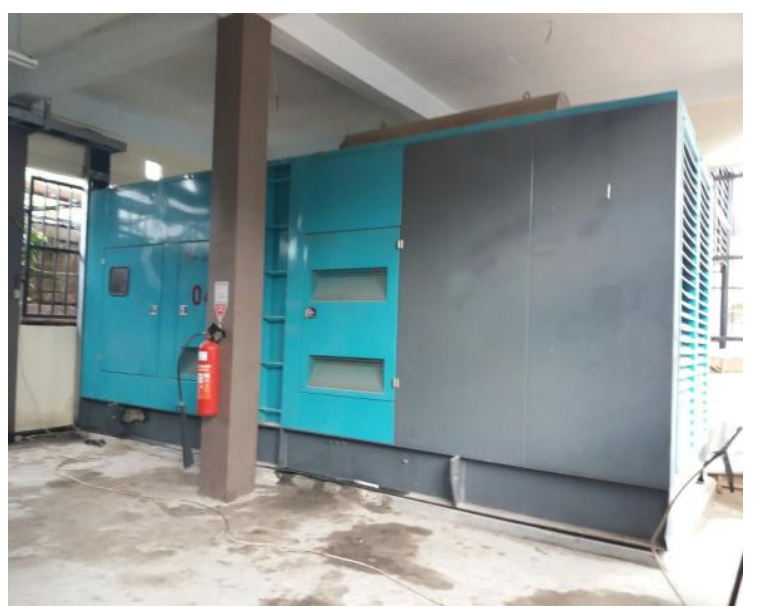

Gambar 9. Generator Set Kapasitas 800 KVA sebanyak 4 Unit yang full otomatis dan sinkronizing

Pengukuran tegangan pada beban menggunakan distribusi listrik tegangan menengah (lihat Tabel 2).

Tabel 2. Pengukuran Tegangan menggunakan Distribusi JTM

\begin{tabular}{llll}
\hline $\begin{array}{c}\text { Gedung } \\
\text { RSUD ULIN }\end{array}$ & $\begin{array}{c}\text { Tegangan } \\
\text { Di Trafo } \\
(\mathrm{U} 1)\end{array}$ & $\begin{array}{c}\text { Tegangan } \\
\text { Di Beban } \\
(\mathrm{U} 2)\end{array}$ & $\begin{array}{c}\text { Droop } \\
\text { Tegangan }\end{array}$ \\
\hline SMF & $372 \mathrm{~V}$ & $371 \mathrm{~V}$ & $1 \mathrm{~V}$ \\
\hline DIAGNOSTIK & $376 \mathrm{~V}$ & $375 \mathrm{~V}$ & $1 \mathrm{~V}$ \\
\hline ANGGREK & $375 \mathrm{~V}$ & $373 \mathrm{~V}$ & $2 \mathrm{~V}$ \\
\hline
\end{tabular}

Manfaat penggunaan Sistem Kelistrikan menggunakan Jaringan Distribusi Tegangan Menengah tersebut antara lain:

1) Pasien Safety lebih terjaga karena perlatan penunjang yang menggunakan listrik akan tetap hidup sehingga peratan dan tindakan terhadap pasien tidak terganggu.

2) Efektifitas pelayanan karena listrik yang disuppy lebih stabil (lihat Tabel 2), Sehingga peralatan yang digunakan untuk pelayanan berfungsi dengan baik

3) Efisiensi terhadap perawatan atau perbaikan peralatan medik maupun non medik karena listrik yang dihasilkan lebih stabil (lihat Gambar 5).

4) Penghematan penggunaan bahan bakar karena genset yang digunakan menyesuaikan beban yang ada di RSUD ULIN

Adapun kekurangan dari sistem kelistrikan menggunakan jaringan distribusi tegangan menengah yaitu:

1) Sumber Daya Manusia yang di miliki harus Kompeten.

2) Jalur Kabel Tegangan Menengah harus Safety ( pakai Uditch).

3) Harus ada spare module elektronik, karena jika rusak maka akan menggangu sistem kelistrikan tersebut.

4) Biaya Investasi Cukup Mahal.

\section{Kesimpulan}

Sistem Kelistristrikan RSUD ULIN yang handal menggunakan distribusi jaringan listrik tegangan menengah $20 \mathrm{KV}$ terintegrasi tersebut dapat diaplikasikan untuk rumah sakit lain yang memiliki area yang cukup luas dan jarak antar gedung cukup jauh. Listrik merupakan jantungnya Rumah Sakit sehingga sistemnya harus sehandal mungkin karena menyangkut Keselamatan Pasien (Patient Safety).

\section{Ucapan Terimakasih}

Pada kesempatan ini penulis mengucapkan terimakasih yang sebesar-besarnya kepada :

1. Direktur RSUD ULIN yang telah memberikan kepercayaan penulis untuk menerapkan Sistem Distribusi Listrik Tegangan Menengah $20 \mathrm{KV}$ Terintegrasi pada RSUD ULIN Banjarmasin.

2. Pemerintah Provinsi Kalimantan Selatan yang sudah mendanai Pembangunan Gedung RSUD ULIN dan memberi kesempatan penulis untuk melanjutkan Studi Program Profesi Insinyur Universitas Lambung Mangkurat, Banjarmasin

\section{Referensi}

1 Imam Robandi, Modern Power System Control, Penerbit ANDI, Yogyakarta, 2009.

2 Imam Robandi, Desain Sistem Tenaga Modern, Penerbit ANDI, Yogyakarta, 2006.

3 Hadi Saadat, Power Sistem Analysis, McGraw-Hill, 1999

4 John J.Grainger, William D Stevension JR, Power Sistem Analysis, McGraw-Hill, 1994 